\title{
Penggunaan Internet of Things (IoT) untuk Pemantauan dan Pengendalian Sistem Hidroponik
}

\author{
Yodi Setiawan $^{1}$, Harlianto Tanudjaja ${ }^{1}$, Sandra Octaviani ${ }^{1}$
}

\begin{abstract}
Internet of things (IoT) has been widely used in development of technology recently. IoT could be interpreted as communication between devices using internet. The advance of IoT technology can ease lot of works, including king control of hydroponic system, so plant treatment can be done anywhere and anytime. Hydroponic is the best solution to people in urban area, who lacks land for greening. Components required in the IoT are devices that have an IoT module, device(s) to connect to Internet such as router or modem, and a database where everythings collected. The purpose of this research is to utilize IoT technology to monitor and control the condition of plants on the hydroponics system remotely. Sensor results processing from end device microcontroller will be sent by XBee to the server microcontroller and displayed to ThingSpeak web server. An application is made for ThingSpeak-connected smartphones that able to monitor and control the system anytime and anywhere. The control will send a logic of one or zero to ThingSpeak and forwarded to the device.

Keywords: Internet of things, hydroponic, XBee, ThingSpeak, application.

ABSTRAK: Internet of things (IoT) sedang marak digunakan dalam perkembangan teknologi saat ini. IoT dapat diartikan sebagai komunikasi antara satu perangkat dengan perangkat lain menggunakan internet. Kemajuan teknologi IoT ini dapat memudahkan berbagai macam pekerjaan, termasuk dalam pengendalian sistem hidroponik, sehingga perawatan tanaman dapat dilakukan dari jarak jauh dan setiap waktu. Hidroponik merupakan solusi terbaik untuk masyarakat di ibukota yang minim lahan untuk penghijauan. Komponen yang dibutuhkan dalam IoT antara lain perangkat yang mempunyai modul IoT, perangkat koneksi ke Internet seperti modem dan router, dan sebuah basis data tempat semuanya terkumpul. Tujuan dari penelitian ini adalah memanfaatkan teknologi IoT untuk memantau dan mengendalikan kondisi tanaman pada sistem hidroponik dari jarak jauh. Pengolahan hasil sensor dari mikrokontroler end device akan dikirim melalui XBee ke mikrokontroler server dan ditampilkan ke web server ThingSpeak. Sebuah aplikasi dibuat untuk smartphone yang terkoneksi dengan ThingSpeak yang dapat memantau dan mengontrol sistem kapan saja dan di mana saja. Kontrol yang dilakukan akan mengirim logika satu atau nol ke ThingSpeak dan diteruskan ke perangkat yang digunakan
\end{abstract}

Kata kunci: Internet of things, hidroponik, XBee, ThingSpeak, aplikasi

\section{PENDAHULUAN}

$\mathrm{B}^{\mathrm{c}}$ eberapa tahun terakhir ini, penggunaan Internet of things (IoT) semakin marak digunakan baik pada perangkat maupun pada produk yang membutuhkan koneksi seperti sensor nirkabel, meter cerdas, dan sistem otomatisasi rumah. Kualitas dari suatu produk IoT dapat dilihat dari beberapa parameter yaitu konsumsi daya yang rendah, jarak jangkauan yang lebih jauh, konektivitas nirkabel dan kemampuan pemrosesan data yang lebih tinggi [1]. IoT dapat diartikan sebagai komunikasi antara satu perangkat dengan perangkat lain menggunakan internet. Kemajuan teknologi IoT ini dapat memudahkan berbagai macam pekerjaan, termasuk dalam pengendalian sistem hidroponik, sehingga perawatan tanaman dapat dilakukan dari jarak jauh dan setiap waktu.

Pola berkebun dengan hidroponik memberi solusi bagi penduduk yang tinggal di perkotaan karena hidroponik adalah cara menanam dengan media air yang merupakan media alternatif pengganti tanah. Penggunaan teknologi IoT memberi kemudahan karena perawatan dapat dilakukan sendiri oleh sistem dan pantauan serta pengendalian terhadap sistem hidroponik dapat dilakukan dimana saja. Sebuah smartphone dapat digunakan sebagai perangkat untuk memantau dan mengendalikan sistem bila pada smartphone tersebut dibuatkan aplikasi berbasis android yang terhubung ke jaringan internet.

\section{INTERNET OF THINGS}

Internet of Things (IoT) adalah sebuah konsep yang mengacu pada penggunaan perangkat dan sistem cerdas yang terhubung untuk memanfaatkan data yang dikumpulkan oleh sensor dan aktuator dalam mesin dan objek fisik lainnya.IoT bekerja dengan memanfaatkan sebuah argumentasi pemrograman dengan tiap perintah argumennya itu menghasilkan sebuah interaksi antara sesama mesin yang terhubung secara otomatis tanpa campur tangan manusia dan dalam jarak berapapun [1].

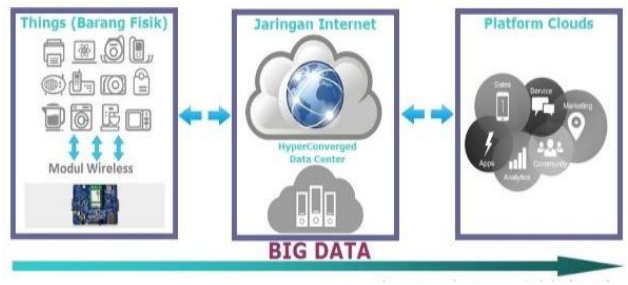

- Gambar 1 Elemen utama IoT

Elemen-elemen utama pada arsitektur IoT yang dapat dilihat pada Gambar 1, yaitu:

1. Barang fisik yang dilengkapi modul IoT.

2. Perangkat koneksi ke Internet seperti modem dan router.

\footnotetext{
${ }^{1}$ Program Studi Teknik Elektro Universitas Katolik Indonesia Atma Jaya
} 
3. Cloud Data Center tempat untuk menyimpan aplikasi beserta basis data.

\section{MIKROKONTROLER ARDUINO UNO}

Mikrokontroler adalah sebuah chip yang berfungsi sebagai pengontrol Central Processing Unit (CPU), memori, Input Output (I/O) tertentu dan unit pendukung seperti Analog-to-Digital Converter (ADC) yang sudah terintegrasi di dalamnya [2]. Arduino Uno memiliki 14 pin masukan dari keluaran digital, dengan 6 pin masukan tersebut digunakan sebagai keluaran PWM, 6 pin masukan analog, $16 \mathrm{MHz}$ osilator kristal, koneksi USB, jack catu daya eksternal, ICSP header, dan tombol reset. Penggunaan papan Arduino dapat dimulai hanya dengan menghubungkannya ke komputer dengan kabel USB atau sumber tegangan dengan adaptor AC-DC dan baterai. Arduino board dapat dilihat pada Gambar 2.

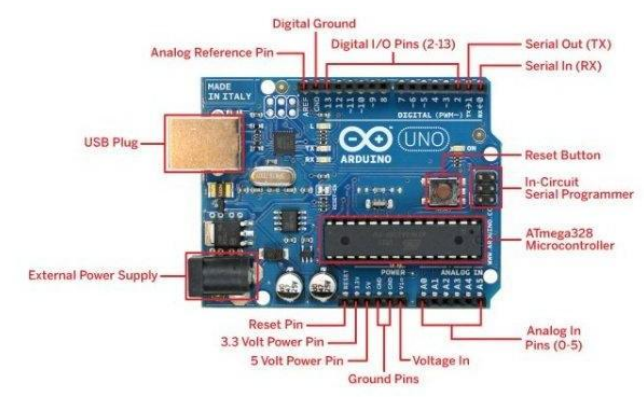

- Gambar 2 Mikrokontroler arduino UNO

\section{PEMANCAR DAN PENERIMA ZIGBEE}

Nama ZigBee sebenarnya merupakan kependekan dari dua kata yaitu zigzag dan bee, yang berarti lebah yang terbang dengan perubahan arah. Namun secara teknik sendiri, ZigBee merupakan sebuah spesifikasi untuk protokol komunikasi tingkat tinggi yang mengacu pada standar IEEE802.15.4. yang berhubungan dengan Wireless Personal Area Networks (WPANs) [3]. Salah satu modul dari ZigBee adalah XBee Pro Series 2.

ZigBee mempunyai 3 tipe perangkat, yaitu:

\section{Coordinator}

Coodinator adalah jaringan ZigBee yang selalu memiliki 1 buah coordinator saja. Perangkat ini dapat memulai suatu jaringan, memilih channel dan PAN ID, menyebarkan alamat-alamat, dan mengijinkan Routers dan End devices untuk masuk ke dalam jaringan. Coordinator tidak boleh berada pada mode sleep dan harus dihidupkan setiap saat.

\section{Router}

Router adalah perangkat ini dapat masuk ke jaringan yang sudah ada dan dapat mengirim, menerima serta merutekan informasi. Routing berlaku sebagai pengirim pesan yang berada di jarak yang jauh sehingga tidak dapat menyampaikan informasi sendiri.

3. End Device

End device merupakan versi sederhana dari router. Perangkat ini dapat masuk ke jaringan yang sudah ada, mengirim danmenerima informasi, tetapi tidak dapat menjadi pengirim pesan antara perangkat-perangkat lain.

\section{MODUL WIFI ESP8266}

XBee merupakan sebuah modul Radio Frekuensi (RF) transceiver menggunakan standar protokol ZigBee dan frekuensi kerja 2,4 GHz dengan antarmuka komunikasi serial UART sehingga lebih mudah dintegrasi dengan mikrokontroler. ESP8266 merupakan modul wifi yang berfungsi sebagai perangkat tambahan mikrokontroler seperti Arduino agar dapat terhubung langsung dengan wifi dan membuat koneksi TCP/IP [4]. Modul ini membutuhkan tegangan sekitar 3.3V dengan memiliki tiga mode wifi yaitu Station, Access Point dan Both (Station and Access Point).

Firmware default yang digunakan oleh perangkat ini menggunakan AT Command, selain itu ada beberapa Firmware SDK yang digunakan oleh perangkat ini berbasis open source yang diantaranya adalah sebagai berikut:

1. NodeMCU dengan menggunakan basic programming Lua.

2. MicroPython dengan menggunakan basic programming Python.

3. ATCommand dengan menggunakan perintah-perintah AT command.

\section{THINGSPEAK}

Platform IoT adalah suatu alat atau suatu program yang digunakan sebagai penghubung antara sensor-sensor yang digunakan dalam perangkat IoT dengan jaringan data. ThingSpeak adalah platform open source aplikasi 
Internet of things (IOT) dan Application Programming Interface (API) untuk menyimpan dan mengambil data dari sesuatu menggunakan protokol Hyper Text Transfer Protocol (HTTP) melalui Internet atau melalui Local area network [5].ThingSpeak memiliki hubungan dekat dengan MathWorks, Inc. Ilustrasi ThingSpeak dapat dilihat pada Gambar 3

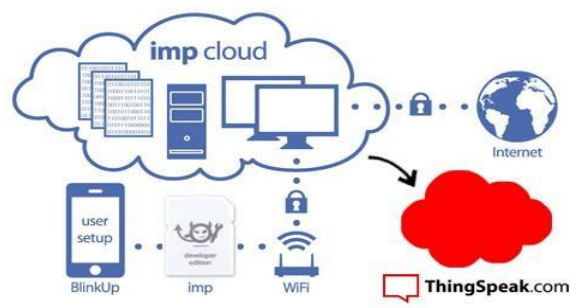

- Gambar 3 Ilustrasi ThingSpeak

\section{MIT App Inventor}

App Inventor memungkinkan pengguna baru melakukan pemrograman komputer untuk menciptakan aplikasi perangkat lunak bagi sistem operasi Android. App Inventor menggunakan antarmuka grafis, serupa dengan antarmuka pengguna pada Scratch dan StarLogo TNG, yang memungkinkan pengguna melakukan drag-anddrop objek visual untuk menciptakan aplikasi yang bisa dijalankan pada perangkat Android .

\section{SENSOR}

Sensor adalah komponen elektronika yang berfungsi untuk mengubah besaran mekanis, magnetis, panas, sinar, dan kimia menjadi besaran listrik berupa tegangan, resistansi dan arus listrik [6]. Sensor-sensor yang digunakan pada penelitian, antara lain:

1. Sensor suhu IC LM35 dan sensor suhu digital DS18B20

2. $\mathrm{PH}$ meter yaitu alat elektronik yang digunakan untuk mengukur $\mathrm{pH}$ (keasaman atau alkalinitas) dari cairan.

3. Sensor Electrical Conductivity yaitu sensor yang menghitung besarnya muatan dari suatu larutan.

\section{HALF DUPLEX}

Half duplex merupakan sistem transmisi data yang dapat melakukan transmisi dua arah dalam satu kanal, tetapi tidak bisa pada saat yang sama. Apabila keduanya mecoba berkomunikasi secara bersama- sama, dalam artian mereka mencoba berbicara secara bersamaan, maka akan terjadi collison (tabrakan). Gambar 4 merupakan sistem transmisi half duplex.

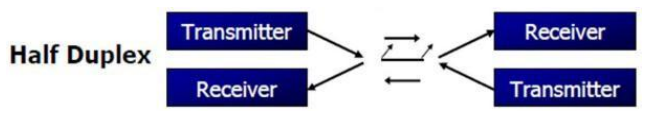

- Gambar 4 Sistem transmisi half duplex

\section{PERANCANGAN}

Hasil pembacaan sensor akan diolah dengan menggunakan mikrokontroler Arduino Mega dan hasil keluaran mikrokontroler akan digunakan sebagai acuan untuk memicu relay juga sebagai masukan bagi XBee penerima. Blok diagram sistem dapat dilihat pada Gambar 5.

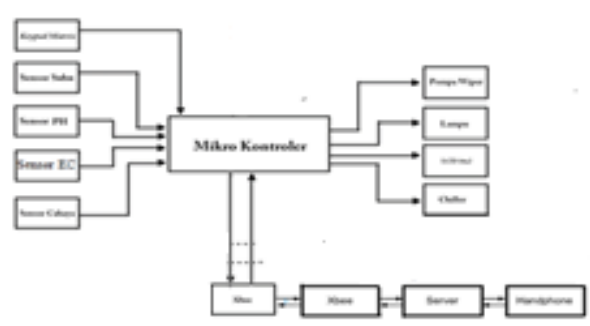

שambar 5 Blok diagram sistem keseluruhan

Seluruh hasil olahan sensor akan dikirim sekaligus dalam satu paket yang diberi header sebagai pemisah keluaran masing-masing sensor dan diterima oleh mikrokontroler Arduino Uno dengan menggunakan XBee yang sudah dikonfigurasi dan terkoneksi satu sama lain. Penerimaan paket oleh XBee penerima akan ditampung dengan menggunakan suatu array. Pemantauan sistem hidroponik dapat dilakukan dengan 2 cara, yaitu melalui :

1. Web server dan smartphone. Setelah paket diterima oleh personal computer (PC) yang berlaku sebagai server, maka dibutuhkan sebuah wifi module yang berguna untuk mengirimkan data yang diperoleh ke 
sebuah platform IoT. Wifi module yang digunakan adalah ESP8266 dan platform yang digunakan pada penelitian ini adalah ThingSpeak. Data yang dikirimkan oleh ESP8266 akan ditampilkan pada field-field yang telah diatur pada ThingSpeak sebelumnya, sehingga pemantauan pemantauan sistem hidroponik dengan menggunakan PC dapat dilakukan.

2. Aplikasi smartphone. Aplikasi smartphone yang digunakan, dibuat dengan menggunakan MIT App Inventor karena adanya sistem drag and drop yang memudahkan pengerjaan. Aplikasi smartphone tersebut dapat dihubungkan denganThingSpeak sehingga pemantauan sama seperti pada ThingSpeak.

Pengendalian manual dapat dilakukan melalui smartphone atau melalui ThingSpeak secara langsung. Prinsip dari pengendalian manual adalah dengan mengubah nilai field aktuator yang diinginkan pada ThingSpeak. Setelah nilai pada field berubah, hasil perubahan tersebut ditangkap oleh Node Microcontroler Unit (NodeMCU) yang merupakan wifi module yang sudah dilengkapi dengan mikrokontroler, lalu kemudian dikirimkan ke mikrokontroler Arduino Uno yang telah terintegrasi dengan XBee. Setelah itu, XBee mengirimkan hasil yang diperoleh ke XBee aktuator yang dihubungkan dengan relay atau LED.

\section{KONFIGURASI XBEE}

Konfigurasi XBee membutuhkan perangkat lunak XCTU dan perangkat keras XBee Carrier atau XBee adaptor sebagai penghubung antara XBee dan XCTU. Suatu sistem jaringan XBee wajib memiliki satu buah koordinator dan router atau end device.

Pada XBee terdapat 2 jenis alamat, yaitu destination address high dan destination address low yang dapat dilihat pada Gambar 6. Destination address high adalah alamat serial umum pada XBee yang selalu sama. Destination address low merupakan alamat unikyang dimiliki oleh masing-masing XBee yang berbeda-beda tiap XBee.

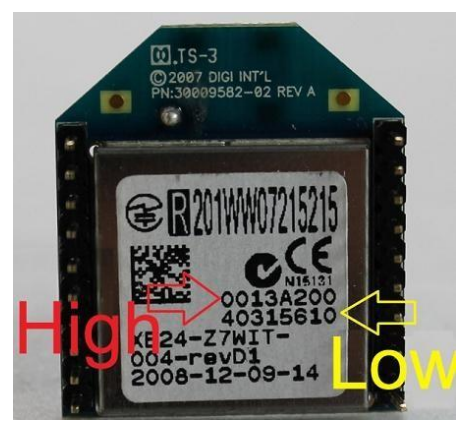

\section{— Gambar 6 Destination address XBee}

Sistem pengalamatan yang digunakan pada penelitian ini adalah unicast atau sering dikenal dengan point to point protocol. Pada konfigurasi pengalamatan secara unicast, destination low address diisi dengan alamat XBee tertentu sesuai dengan destination low address XBee tujuan.

Hal pertama yang diperlukan untuk mengonfigurasi XBee adalah menghubungkan XBee dengan XBee carrier lalu dihubungkan ke PC. Setelah itu, buka program XCTU dan klik discover devices pada bagian pojok kiri atas. Jendela Discover Radio Devices akan muncul, lalu pilih port yang menghubungkan XBee dengan komputer dan klik tombol next. Bila XBee dan komputer sudah terhubung maka radio module XBee yang tersambung akan muncul, lalu klik finish. Setelah itu, klik XBee yang ingin dikonfigurasi, lalu akan muncul jendela seperti Gambar 7.

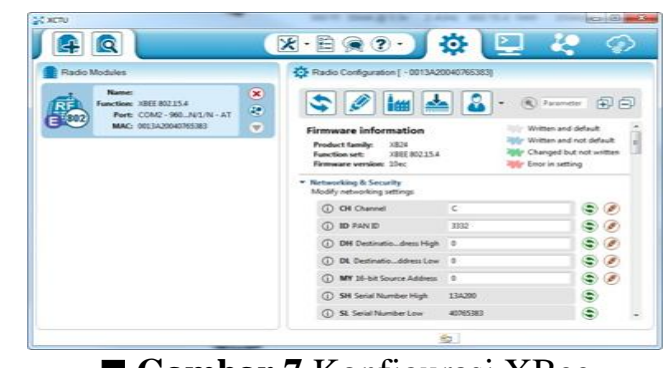

- Gambar 7 Konfigurasi XBee

Firmware XBee dapat diubah sesuai kebutuhan, dan karena sistem yang digunakan adalah sistem unicast maka firmware diubah menjadi versi terbaru dengan mode yang bisa unicast. PAN ID adalah sebuah ID yang digunakan agar semua XBee berada pada jaringan komunikasi yang sama. Konfigurasi PAN ID yang digunakan adalah 1111 sehingga PAN ID seluruh XBee yang digunakan diubah menjadi 1111 agar dapat saling berkomunikasi.

Alamat dapat diatur dengan cara mengisi Destination Address High dan Destination AddressLow sesuai dengan XBee tujuan BaudRate default i XBee adalah 9600, sedangkan BaudRate dari ESP8266 adalah 115200, agar 
keduanya dapat berkomunikasi satu sama lain maka salah satu dari keduanya harus diubah, dalam hal ini BaudRate XBee diubah menjadi 115200. XBee dapat menjadi coordinator dengan memilih coordinator enabled (CE) menjadi enabled. Node Identifier (NI) dapat diubah sesuai dengan keperluan untuk memudahkan identifikasi XBee mana yang digunakan.

\section{KONFIGURASI ESP8266}

ESP8266 merupakan sebuah wifi module yang memungkinkan sebuah perangkat terkoneksi ke internet. ESP8266 menggunakan AT command sebagai bahasa pemrograman default- nya. Flashing firmware terlebih dahulu untuk memungkinkan ESP8266 memperoleh seluruh konten terbaru. Modul ESP8266 dapat dilihat pada Gambar 8 .

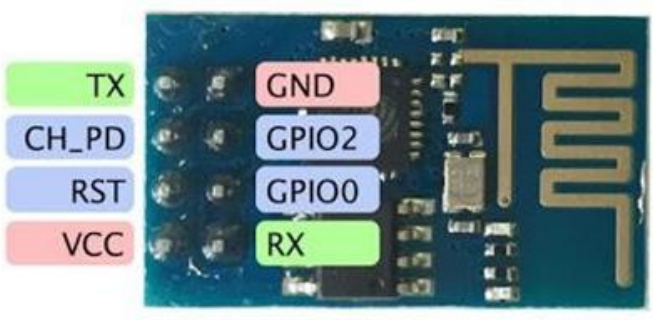

- Gambar 8 Modul ESP8266

Paket yang dikirim dari mikrokontroler Arduino Mega memiliki informasi keluaran dari 4 buah sensor, sehingga membutuhkan header dan header yang digunakan dapat dilihat pada Gambar 9.

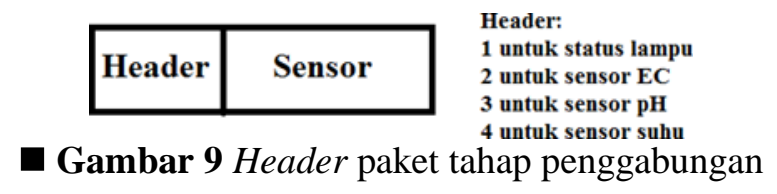

Hasil mikrokontroler server akan dikirimkan ke IoT platform ThingSpeak menggunakan wifi module ESP8266. ThingSpeak dikonfigurasi terlebih dahulu dengan membuat akun MathWorks dan mengkonfigurasi delapan field yang akan digunakan. Field 1 dan 2 akan berubah sesuai dengan angka yang dibaca oleh sensor. Selanjutnya, buat aplikasi pada smartphone untuk memudahkan pembacaan dan pengendalian. Aplikasi pada smartphone dibuat menggunakan MIT App Inventor.

\section{HASIL PENGUJIAN NODE END DEVICE}

Pada tahap percobaan, mikrokontroler end device digunakan untuk memantau sensor suhu DS1730 dan LM 35. Keluaran hasil dari pengunggahan program ke mikrokontroler Arduino end device dapat dilihat pada Gambar 10. Data pembacaan sensor tersebut akan diperbaharui setiap 3 detik yang diatur dengan menggunakan perintah delay.

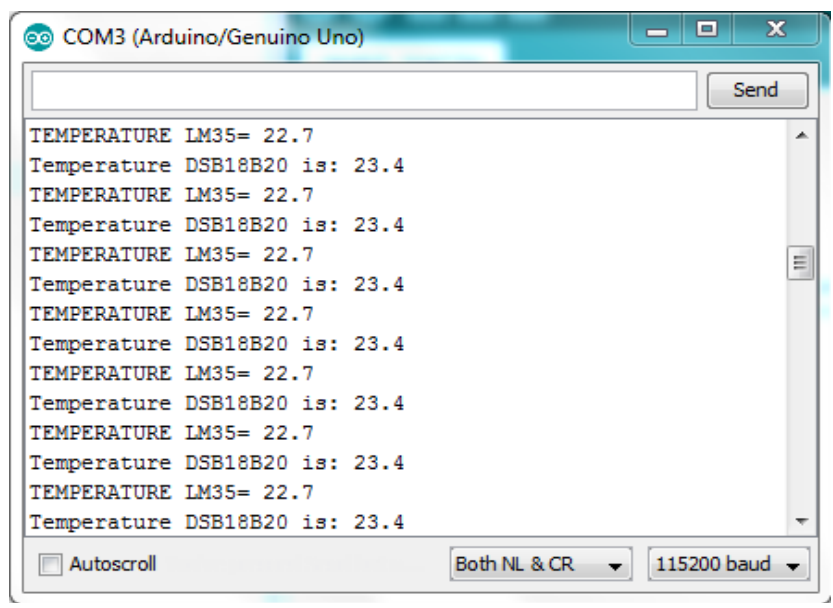

- Gambar 10 Hasil keluaran node end device

\section{HASIL PENGUJIAN NODE SERVER}

Pada node server, mikrokontroler akan menampilkan hasil pembacaan sensor yang dikirim dari mikrokontroler end device dan AT command agar terhubung dengan ThingSpeak. Hasil tersebut dapat dilihat pada Gambar 11. 


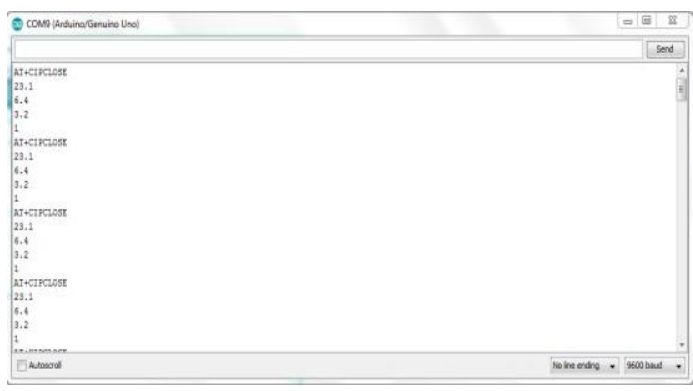

- Gambar 11 Hasil keluaran node server

\section{HASIL PENGUJIAN THINGSPEAK}

ThingSpeak digunakan sebagai IoT platform pada penelitian ini. ThingSpeak terdiri dari 8 buah field, 4 digunakan sebagai pemantauan hasil pembacaan sensor, 4 sisanya digunakan sebagai aktuator status. Hasil pengujian pada ThingSpeak dapat dilihat pada Gambar 12 sampai 19.

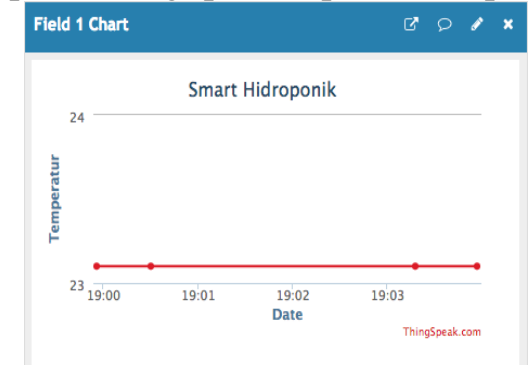

- Gambar 12 Field 1 sensor suhu

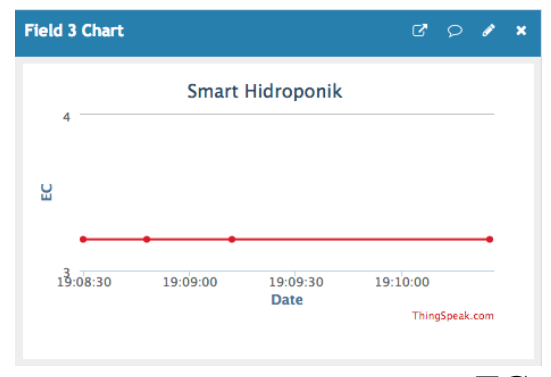

- Gambar 14 Field 3 sensor EC

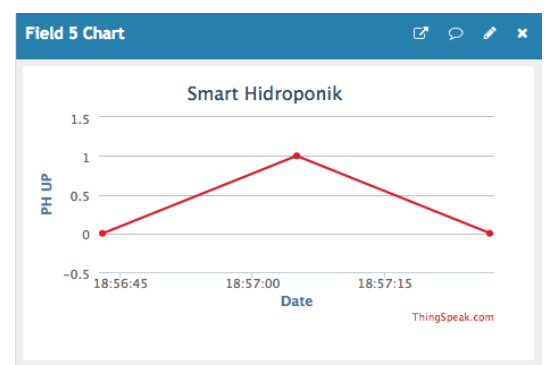

- Gambar 16 Field 5 PH up

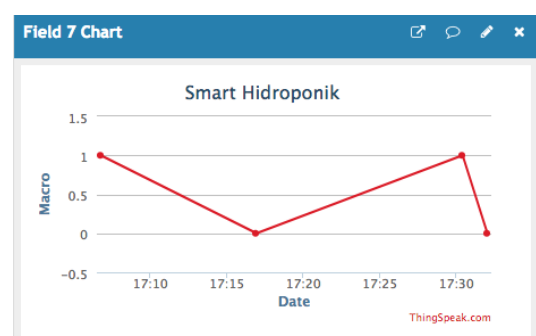

- Gambar 18 Field 7 macro

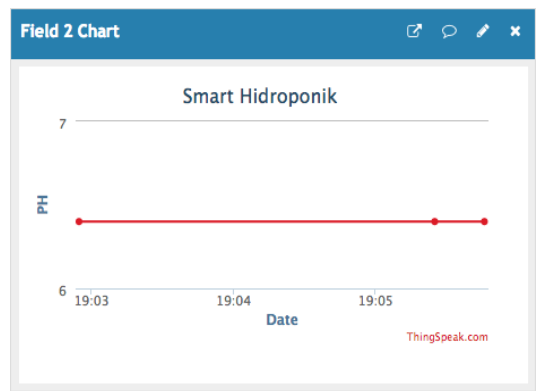

- Gambar 13 Field 2 sensor PH

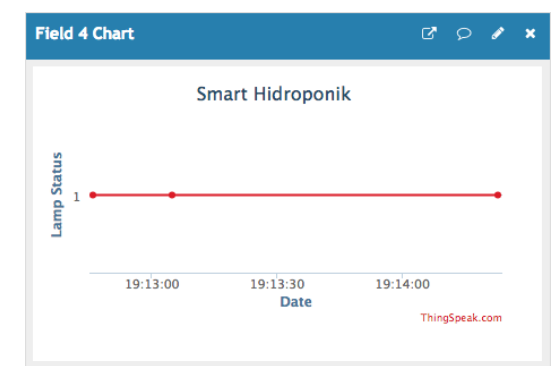

- Gambar 15 Field 4 Status lampu

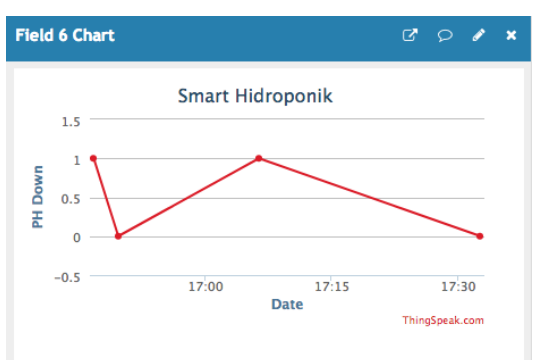

- Gambar 17 Field 6 PH down

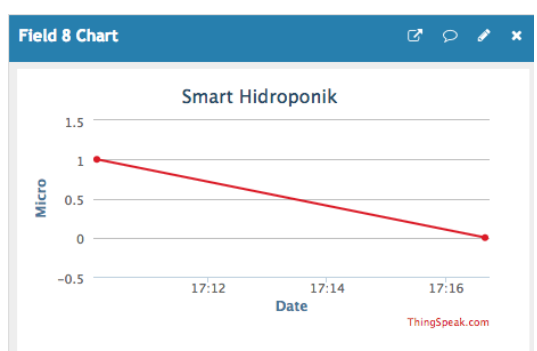

- Gambar 19 Field 8 micro

Oleh karena keterbatasan ThingSpeak, ThingSpeak hanya dapat melakukan pembaharuan setiap 13 detik pada performa terbaiknya, walaupun sistem mampu melakukan update setiap 3 detik. Selain itu, ThingSpeak sangat membutuhkan internet yang cepat agar dapat terus menerus memperbaharui pembacaan sensor, jika internet tidak berada pada kecepatan tinggi,ThingSpeak tidak akan memperbaharui pembacaan sensor. 


\section{HASIL PENGUJIAN APLIKASI}

MIT App Inventor 2 digunakan untuk membuat aplikasi pada smartphone. Aplikasi yang telah dibuat dapat dilihat pada Gambar 20.

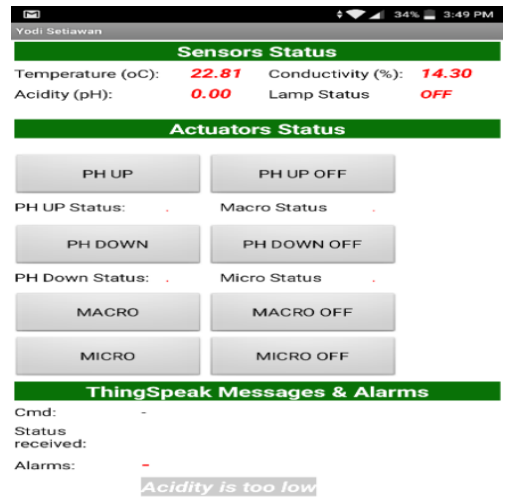

- Gambar 20 Aplikasi Smart Hydroponic

Pada aplikasi yang dibuat terdapat 4 buah tombol, penekanan tombol "phup on" mengubah field 5 ThingSpeak menjadi angka 1, sedangkan penekanan tombol "phup off" mengubah field 5 ThingSpeak menjadi angka 0. Field 5 pada ThingSpeak digunakan untuk menyalakan atau mematikan LED sebagai indikator untuk menghidupkan phup. Field 6 ThingSpeak digunakan untuk mengatur LED yang mengatur phdown. Untuk mengatur Field 6 ThingSpeak dapat menggunakan "phdown on" agar membuat nilai 1 atau "phdown off" agar membuat nilai 0 .

Selain dua aktuator yang telah disebutkan sebelumnya, masih terdapat dua aktuator lainnya yang berfungsi untuk memberikan macro nutrition dan micro nutrition. Macro nutrition diatur oleh field 7 ThingSpeak dan micro nutrition diatur oleh field 8 ThingSpeak. Field 7 ThingSpeak dapat bernilai 1 dengan menekan tombol "macro on", sedangkan bernilai 0 dengan menekan tombol "macro off". Field 8 Thinspeak dapat bernilai 1 dengan menekan tombol "micro on", bernilai 0 dengan menekan tombol "micro off".Sistem komunikasi antara smartphone dengan ThingSpeak menggunakan sistem komunikasi half duplex. ThingSpeak akan memberikan sinyal terus-menerus terhadap aplikasi yang telah dibuat dan hanya mempunyai delay 3 detik. Terdapat masalah yang timbul apabila aplikasi mengirimkan respon ke ThingSpeak, hal tersebut dapat terjadi apabila ada penekanan tombol pada aplikasi. Penekanan tombol pada aplikasi akan mengubah nilai field pada ThingSpeak yang berarti akan mengirimkan suatu sinyal ke ThingSpeak, akan tetapi ThingSpeak juga terusmenerus mengirimkan sinyal kepada aplikasi. Oleh karena itu, terjadi gangguan yang mengakibatkan jaringan komunikasi antara ThingSpeak ke aplikasi terhenti dan mengakibatkan aplikasi menjadi error dan akan muncul pop up message "Bad arguments" seperti pada Gambar 21 sehingga harus menutup kembali aplikasi dan membukanya kembali. Aplikasi akan berjalan normal kembali jika aplikasi sudah mendapat respons dari ThingSpeak kembali.

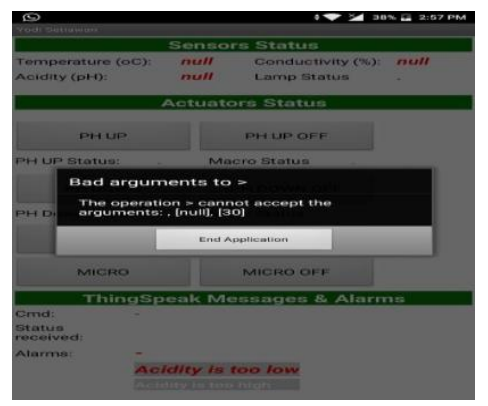

Gambar 21 Error message

KESIMPULAN

Berdasarkan hasil penelitian maka dapat disimpulkan beberapa hal antara lain:

1. Sistem pemantauan dan pengendalian smart hydroponic dapat dilakukan melalui web server ThingSpeak atau aplikasi smartphone.

2. ThingSpeak sebagai web server yang digunakan sangat membutuhkan koneksi internet yang cepat dan stabil. Bila koneksi internet tidak sesuai dengan kebutuhan dari ThingSpeak maka ThingSpeak tidak akan memperbaharui nilai keluaran. 
3. Transmisi data antara ThingSpeak dan aplikasi smartphone menggunakan sistem half duplex, sehingga terjadi masalah apabila ada pengiriman data dari aplikasi ke ThingSpeak.

\section{DAFTAR PUSTAKA}

[1]. FlyingEagle. 2016. Penjelasan dan Cara Kerja Konsep Internet of Things,(http://www.mobnasesemka.com/internet-of-things/, diakses 21 Maret Aulia, M. S. 2017.

[2]. Javed, A. 2016. Building Arduino Projects for the Internet of Things. Lake Zurich, Illinois: Apress.

[3]. Hadiyoso, S., et al. 2014. Studi Level Daya Pada Perangkat Zigbee Untuk Kelayakan Aplikasi Real time Monitoring. Makalah disajikan dalam 6th Digital Information \&System Conference (DISC), Univ,Kristen Maranatha,Bandung, Oktober 2014

[4].Scharler,H.2012. Connecting Electric Imp to ThingSpeak IoT Data Services. Manhattan, Mathworks

[5]. Mengenal Platform IoT,(http://sh4retech.blogspot.co.id, diakses 10 Februari 2018) Burd, B. 2015. Android Application Development All-in-One For Dummies. Hoboken, New Jersey: John Willey and Sons.

[6]. Matula, S., Batkova, K., dan Legese, W. L. Laboratory Performance of Five Selected Soil Moisture Sensors Applying Factory and Own Calibration Equations for Two Soil Media of Different Bulk Density and Salinity Levels.Sensor 16(11): 390-398 